\title{
Satisfaction of the Primary Care, Mental Health, and Dental Health Clinicians of the National Health Service Corps Loan Repayment Program
}

\author{
Donald E. Pathman, MD MPH \\ Thomas R. Konrad, PhD \\ Robert G. Sewell, PhD, MA \\ Jackie Fannell \\ Thomas Rauner
}

\begin{abstract}
The National Health Service Corps (NHSC) aims to foster a positive service experience for its clinicians to promote long-term retention. We assess the satisfaction of primary care, dental, and mental health clinicians in the NHSC's Loan Repayment Program (LRP). Survey data are from 1,193 clinicians (72.4\% response) who completed NHSC LRP contracts in 16 states from July 2015 through December 2016. Eighty-one percent reported overall satisfaction with their work and practice, without differences across disciplines. Nearly 95\% were satisfied with the mission and patients of their practices. Fewer clinicians were satisfied with compensation (51\%) and time demands of work (36\%). Ninety-four percent reported the NHSC experience met or exceeded their expectations, and $94 \%$ recommend the NHSC LRP to others. In summary, the NHSC LRP experience is generally positive for clinicians of all disciplines. Clinicians' issues with their incomes and with the time demands of their work deserve attention from the NHSC.
\end{abstract}

Key words: National Health Service Corps, education loan repayment, clinician satisfaction, clinician workforce policy.

$\mathrm{T}$ he quality of any clinician's work life affects matters far beyond that clinician's personal happiness. This is true for clinicians serving in the National Health Service Corps (NHSC), who provide care to socioeconomically challenged patients in chronically understaffed clinics and under-resourced communities. Like all clinicians, those in

DONALD E. PATHMAN is affiliated with the Cecil G. Sheps Center for Health Services Research and Department of Family Medicine, University of North Carolina at Chapel Hill. THOMAS R. KONRAD is affiliated with the Cecil G. Sheps Center for Health Services Research, University of North Carolina at Chapel Hill. ROBERT G. SEWELL is affiliated with the Office of Healthcare Access, Section on Rural and Community Health Systems, Division of Public Health, Alaska Department of Health and Social Services. JACKIE FANNELL is affiliated with the Foundation for Health Leadership and Innovation. THOMAS RAUNER is affiliated with the Primary Care Office and Office of Rural Health, Nebraska Division of Public Health. Please address all correspondence to: Donald E. Pathman, University of North Carolina at Chapel Hill, 725 Martin Luther King Blvd, UNC CB\# 7595, Chapel Hill, NC, 27599. Phone: 919-966-4270; Fax: 919-966-3811; Email: Don_Pathman@unc.edu. 
the NHSC who are happy in their jobs can be expected to provide better quality care, communicate better with patients, and have happier patients who are more likely to follow recommended care than clinicians who are not happy in their jobs. ${ }^{1-5}$ Also like all clinicians, NHSC practitioners doing work they find satisfying are less likely than others to leave their practices, which lessens care disruptions for patients and reduces practices' costs to recruit replacements. ${ }^{6-8}$ Supporting satisfied clinicians helps meet the NHSC's goal for long-term workforce retention in underserved areas. ${ }^{9-11}$

When last formally studied nationally and published 25 years ago, physicians working in underserved areas who had committed as students to the NHSC's original Scholarship Program were less satisfied than other physicians in these settings, and they were less likely to remain long-term. ${ }^{12-13}$ An unpublished national evaluation 20 years ago found that only half of NHSC clinicians were satisfied overall with their jobs and fewer than half reported that their families were satisfied in the community. ${ }^{14}$

Today's NHSC is different in many ways. Most (92\%) NHSC clinicians currently serve in the Loan Repayment Program (LRP), ${ }^{15}$ which recruits practitioners after their training when they can know the sites and communities available to them then and select what best fits them and their families. Over the past 20 years, the NHSC's workforce has also tripled in size and greatly diversified: it now includes as many nurse practitioners as physicians (1,500 each), more than 2,900 mental health workers of various disciplines, and nearly 1,400 dentists and dental hygienists. ${ }^{15,16}$

The NHSC also now identifies its clinicians as one type of customer, stresses a customer service orientation, and aims to promote a fulfilling experience for its clinicians. The NHSC tries to identify and resolve job challenges as they arise for individuals and permits clinicians to move to different qualifying practice settings when necessary. Clinicians can elect to serve part-time and may teach students while serving. The NHSC also seeks to foster better communication with its clinicians through its website, conferences and site visits, and it promotes supportive online communities and mentoring relationships. The NHSC monitors satisfaction through regular internal clinician surveys. ${ }^{17,18}$

Little is known and reported about how clinicians of the various disciplines now participating in the NHSC fare in a program that has made fundamental changes over the decades and aims to support its participants' needs. Retention in service sites has improved over the years, ${ }^{11,19}$ likely reflecting an improved NHSC experience, but this is untested. The goal of this study is to describe and compare how the variety of disciplines of today's NHSC Loan Repayment Program regard their work, practices, and communities, as well as how they view their participation in the NHSC overall.

\section{Methods}

Subjects and data collection. Data for this study were drawn from questionnaire information routinely collected from all clinicians serving in the NHSC's LRP within the states participating in the Multi-State Clinician Retention Collaborative. ${ }^{20}$ The Collaborative-a joint effort of state primary care offices, offices of rural health, and other agencies that help staff safety-net practices-gathers uniform questionnaire data from clinicians as they serve in support-for-service programs, including scholarship, loan repayment, and forgivable loan programs. Data are principally intended to help 
participating state offices support individual clinicians as they serve, as well as to provide hard outcome data to programs.

The Collaborative receives roster data from the Bureau of Health Workforce from its U.S. Bureau of Clinician Recruitment and Service Management Information System Solution (BMISS) for all NHSC clinicians in participating states. These clinician data are incorporated into the Collaborative's Clinician Management and Retention Data System, which automates the processes of emailing questionnaire invitations and reminders to each clinician on a schedule driven by their contract dates. Invitations contain links to online questionnaires. Clinician participation is voluntary but strongly encouraged by staff in states' participating offices.

The target population for this study was all clinicians completing initial and renewal NHSC LRP contracts during the 18-month period from July 1, 2015 through December 31, 2016 within the Collaborative's 16 states that had LRP program completers during this period. A total of 1,886 clinicians completed one or more NHSC LRP contracts during this period, of whom 1,366 (72.4\%) responded to end-of-contract questionnaires. Survey response rates did not vary across disciplines $(\mathrm{p}=.82)$. For those completing multiple contracts during the study period, the questionnaire from the earliest contract was used.

For analyses, we combined or omitted the smallest disciplines. Specifically, we combined the 10 certified nurse midwives, 22 psychiatric nurse practitioners, and six psychiatric nurse therapists with 192 other nurse practitioners into a single "advanced practice nurse" group. We omitted dental hygienists $(n=39)$ and marriage and family therapists $(n=27)$, yielding a final analytical sample of 1,193 clinicians within seven disciplines.

Questionnaires. The "end-of-contract" questionnaire queried clinicians' agreement with 23 statements about selected aspects of their jobs and practices and their work and practices overall, drawn from the Physician Worklife Study survey instrument. ${ }^{21,22}$ Typical items included: "Work rarely encroaches upon my personal time," "Staff in my practice support my professional judgement," and "Overall I am pleased with my current work." Five Likert-scaled response options ranged from "strongly agree" to "strongly disagree," with a central neutral option.

The questionnaire included eight items reflecting clinicians' perceptions of key aspects of their and their families' fit with their communities, e.g., "I/We have access to most of the things we like to do." These items, based on the literature, have been used in studies of clinician satisfaction, community integration, and job retention with a variety of clinician groups and settings, with demonstrated face, convergent, predictive, and discriminant validity. ${ }^{11,12,14,23-25}$

The questionnaire also contained three Likert-scaled questions commonly used to assess people's satisfaction with social service and educational programs and have been used previously with NHSC participants. ${ }^{11}$ Clinicians rated: (a) the extent to which the NHSC LRP met, fell short of, or exceeded their expectations; (b) how likely they are to recommend the NHSC LRP to other practitioners; and (c) their satisfaction with three aspects of the NHSC (financial support, interactions with program staff, participation in the NHSC overall). Clinicians were promised anonymity specifically for this group of questions to promote open disclosure. 
Data from BMISS on each clinician's discipline, date of birth, gender, practice setting type, and location were verified by clinicians in questionnaires, completed three months into their service contracts. In these early questionnaires, clinicians also reported their demographic characteristics, and the importance that financial support and providing care for underserved communities played in their decisions to commit to the NHSC LRP. $^{12-14}$ Service site ZIP codes were linked to Rural-Urban Continuum Codes (RUCA); ${ }^{26}$ RUCA codes 1 to 3 were designated as urban and 4 to 10 as rural.

Analysis. Analyses were principally descriptive, presenting group percentages reporting positively on each outcome measure. Likert-scaled question data were dichotomized. Although we present differences between disciplines assessed with chi-square tests or ANOVA using a two-tailed .05 significance level, we principally relied on the magnitudes of group differences to interpret their importance. Given high item completion rates $-98 \%$ for evaluation items and no lower than $94 \%$ for demographic items-no missing value imputation was performed.

Data from the 21 survey items querying specific aspects of clinicians' job and work satisfaction were collapsed into fewer factors to simplify analyses and the presentation of findings. Exploratory factor analysis with varimax rotation and Kaiser normalization found that 18 of these survey items grouped cleanly into five factors, each with two to eight items: mission orientation and patients (Cronbach's alpha $=.82$ ); administration, relationships and organizational stability (.88); work's time demands (.77); compensation (.56); and community involvement (.81). The alpha reliability coefficient for the two-item compensation scale is lower than generally accepted, but we retained this scale in analyses because alphas are imperfect estimates of internal reliability for two-item scales, ${ }^{27}$ and because of the importance of workers' satisfaction with their income and benefits. The three questionnaire items that did not load cleanly on these five factors were omitted. The twenty-second and twenty-third items assessing overall satisfaction with work and the practice, respectively, were combined as an "overall work and practice satisfaction" scale for analyses (alpha=.84).

This study was exempted from human subjects review by the University of North Carolina at Chapel Hill Office of Human Research Ethics (Study \# 12-0626; February 15,2017$)$.

\section{Results}

Participants by state and discipline. The number of clinicians completing NHSC LRP contracts within each state varied, reflecting variation in numbers of NHSC eligible and filled sites across states, as well as how recently states had joined the Collaborative. Number of clinician LRP participant respondents by state were: Missouri, 276; California, 237; North Carolina, 167; Minnesota, 89; New Mexico, 87; Arkansas, 79; South Carolina, 55; Kentucky, 47; North Dakota, 41; Alaska, 37; Nebraska, 28; Nevada, 26; Wisconsin, 13; Delaware, 5; Montana, 4; and Oregon, 2.

Respondents included 639 primary care practitioners, 169 dentists and 385 mental health clinicians (Table 1). Physicians were the largest discipline $(\mathrm{n}=256)$ and licensed clinical social workers the smallest $(\mathrm{n}=113)$.

Demographic characteristics. Clinicians completing NHSC LRP contracts were 


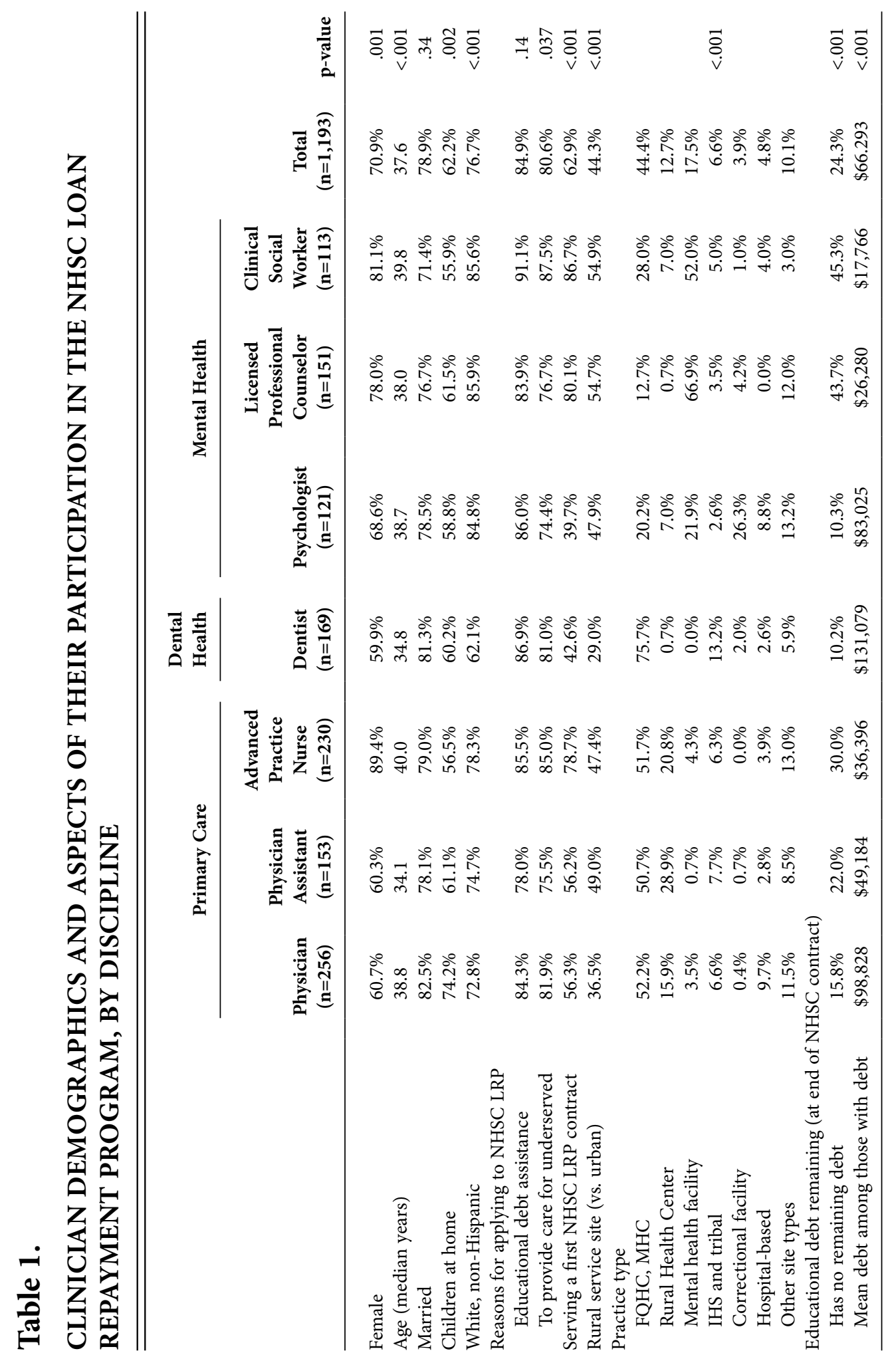


predominantly female (71\% overall), non-Hispanic White (77\%) and married (79\%), and $62 \%$ had children at home (Table 1 ). Among the seven discipline groups, meaningful differences in demographic characteristics were principally that physician assistants and dentists averaged three to six years younger than others, and more dentists were underrepresented minorities.

NHSC Loan Repayment Program participation. Self-reported motivations for committing to the NHSC LRP were fairly comparable across discipline groups (Table 1). Generally, about $80 \%$ of clinicians of each discipline indicated that they needed the assistance repaying education debt and a comparable percentage wanted to provide care for the underserved. Most clinicians indicated both reasons. Overall, 63\% of these clinicians were serving their first contract with the NHSC LRP but percentages varied greatly across disciplines, from about $40 \%$ of dentists and psychologists to more than $80 \%$ of licensed professional counselors and clinical social workers.

Half of physicians, physician assistants, and nurse practitioners, and three-quarters of dentists served in federally qualified health centers (FQHC) ${ }^{28}$ or similar health centers, but about one-quarter or less of the mental health discipline professionals worked in such centers. More than half of licensed professional counselors and clinical social workers served in mental health facilities, but very few primary care clinicians and dentists served there. A quarter of psychologists but few others worked in correctional facilities. Forty-four percent of clinicians overall served in rural areas, ranging from $29 \%$ of dentists and $37 \%$ of physicians to nearly $55 \%$ of licensed professional counselors and clinical social workers.

Clinicians' satisfaction with their work and practices. Eighty-one percent of these NHSC clinicians reported overall satisfaction with their work and practices, without significant differences across disciplines (Fig. 1). Disciplines expressed differing levels of satisfaction with various aspects of their work and practices. Nearly 95\% were satisfied-agreeing or strongly agreeing with various positive statements-with the mission orientation and patients of their practices, and 70\% were satisfied with their practices' administration/internal relationships/stability. On the other hand, only half (51\%) of these NHSC clinicians were satisfied with their compensation, and just 36\% were satisfied that the time demands of work did not encroach on their personal lives. The three primary care disciplines were generally similar in their proportions satisfied with each aspect of their work and with their work overall, and the three mental health disciplines were also comparable to one another. However, mental health clinicians were more likely than primary care clinicians to be satisfied with the time demands of their work ( $44 \%$ vs. $29 \%$, respectively; $\mathrm{p}<.001$ ). Advanced practice nurses were least satisfied with their compensation.

Given their experiences, $82.5 \%$ indicated they would recommend their practices to others of their discipline, without significant differences across disciplines, which ranged from $78.5 \%$ of advanced practice nurses to $87.2 \%$ of licensed professional counselors $(\mathrm{p}=.23)$ (data not shown in tables).

Community satisfaction for clinicians and families. Clinicians indicated satisfaction with their community by responding "agree" and "strongly agree" (vs. "neutral," "disagree," and "strongly disagree") to positive statements about their communities. 


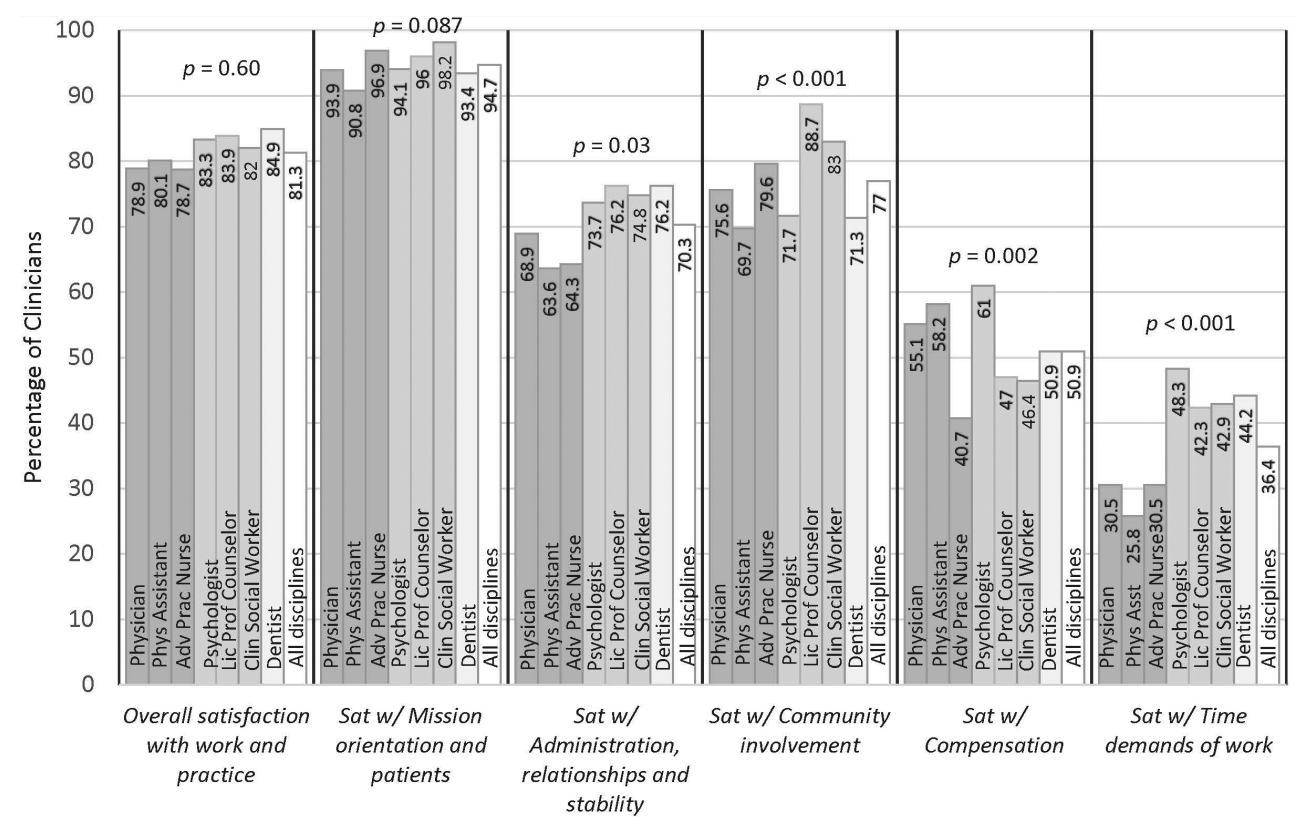

Figure 1. Percentage of clinicians satisfied a overall and with various aspects of their practice and work, by discipline. ${ }^{\text {a }}$

Note: ${ }^{a}$ Item and scale response average in the "agree" to "strongly agree" range.

Overall, $82 \%$ of married NHSC clinicians felt their spouses were happy in their local community, and among those whose spouses wanted to work, $75 \%$ reported that their spouses were happily employed (Fig. 2). Differences in reported spousal satisfaction across disciplines were generally small and not statistically significant.

Eighty-seven percent of clinicians with children at home reported that their children were happy in the community, and 78\% reported their children's needs were well met by their community. Psychologists were the most likely and dentists least likely to indicate that their children were happy ( $94 \%$ vs. $76 \%$, respectively) and well provided for $(89 \%$ vs. $69 \%)$.

Three-quarters of clinicians of all disciplines agreed that they and their families enjoyed the activities their communities offered and that they had access to most of the things they liked to do.

Impressions of the NHSC experience. Ninety-four percent of these clinicians completing NHSC LRP contracts rated their overall participation in the NHSC as "very good" or "excellent" (top two of five Likert response options) (Table 2). Similarly, 89\% rated their interactions with NHSC staff and 85\% rated the program's financial support "very good" or "excellent." Ratings were generally higher for mental health practitioners and advanced practice nurses.

Seventy-one percent of clinicians indicated that their NHSC experience exceeded their expectations (Likert values 7-10 out of 10 response options) and another $23 \%$ indicated that their expectations were met (responses 5 or 6). The NHSC experience 


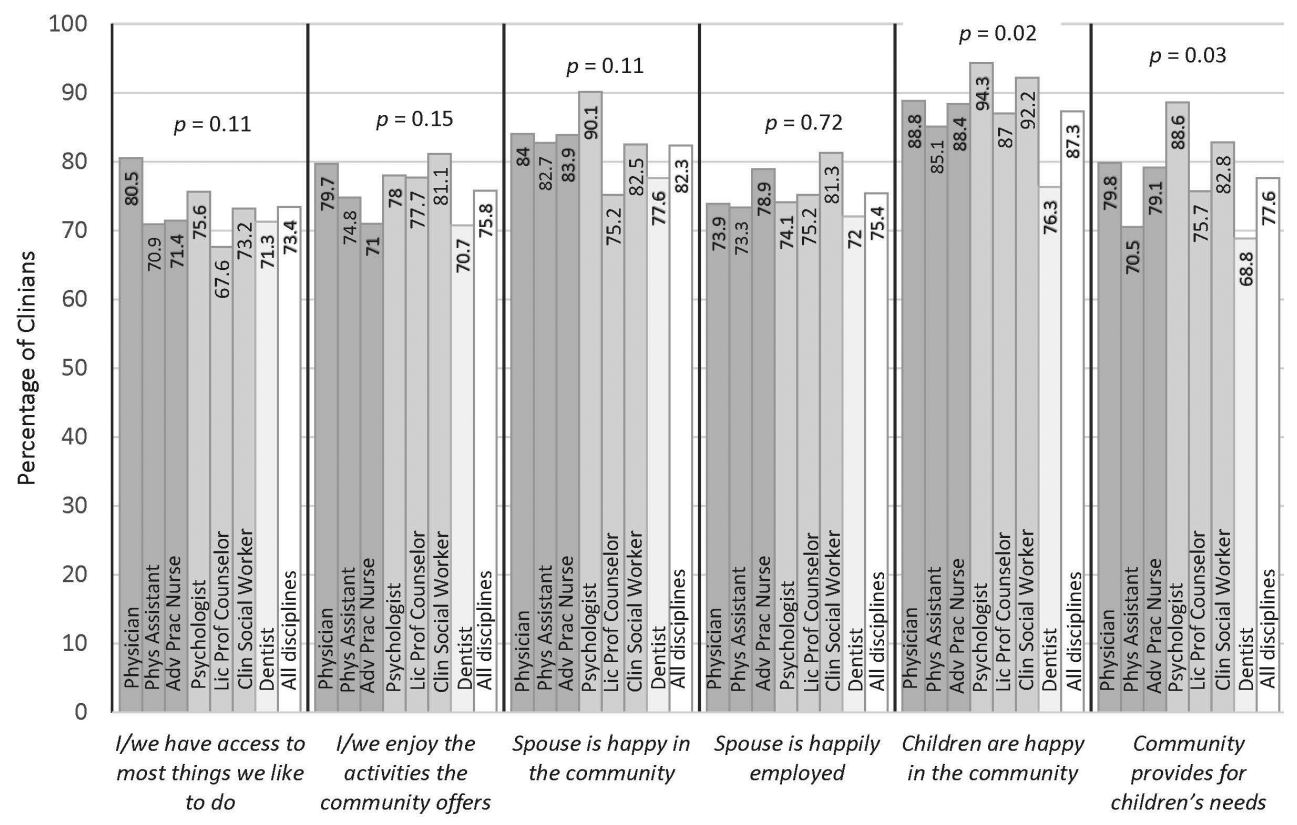

Figure 2. Percentage of clinicians and families satisfied with the community, by discipline. ${ }^{\mathrm{a}}$

Note: ${ }^{\text {a }}$ The denominators in percentage calculations for each discipline vary as appropriate to each area of satisfaction queried:all clinicians; married clinicians; married clinicians whose spouses want to work; and clinicians with children at home.

fell short of expectations for only $6 \%$ (responses 1-4). Licensed professional counselors and clinical social workers were most likely to report their expectations were exceeded.

Almost 94\% of clinicians indicated that they "probably" or "definitely" (top two of five Likert response options) would recommend the NHSC LRP to other practitioners.

Comparing clinicians serving initial versus renewal contracts. It may be that clinicians who elect to renew their NHSC contracts overrepresent those with positive experiences during their initial contracts. To assess for the possibility of biased satisfaction ratings due to how study participants and their questionnaires were selected, we tested if the 414 clinicians (37\%) in the study sample who were serving renewal contracts reported more favorable experiences than the 750 clinicians (63\%) serving initial contracts. We found no meaningful or statistically significant differences between the two groups in the proportions satisfied with work overall or with satisfaction on any of the six tested specific aspects of their practices and jobs. The groups also gave comparable assessments of how well communities served their spouses and children, and their family needs. Clinicians serving first contracts were no more or less likely than those in renewal contracts to recommend their practices $(80.8 \%$ vs. $83.9 \%, \mathrm{p}=.41)$ and the NHSC LRP (94.6\% vs. $93.9 \%, \mathrm{p}=.47$ ) to others of their discipline. The only between-group difference found was that clinicians serving initial contracts were slightly more likely to report that the NHSC met or exceeded their expectations $(95.3 \%$ vs. $91.2 \%, \mathrm{p}=.04)$. 


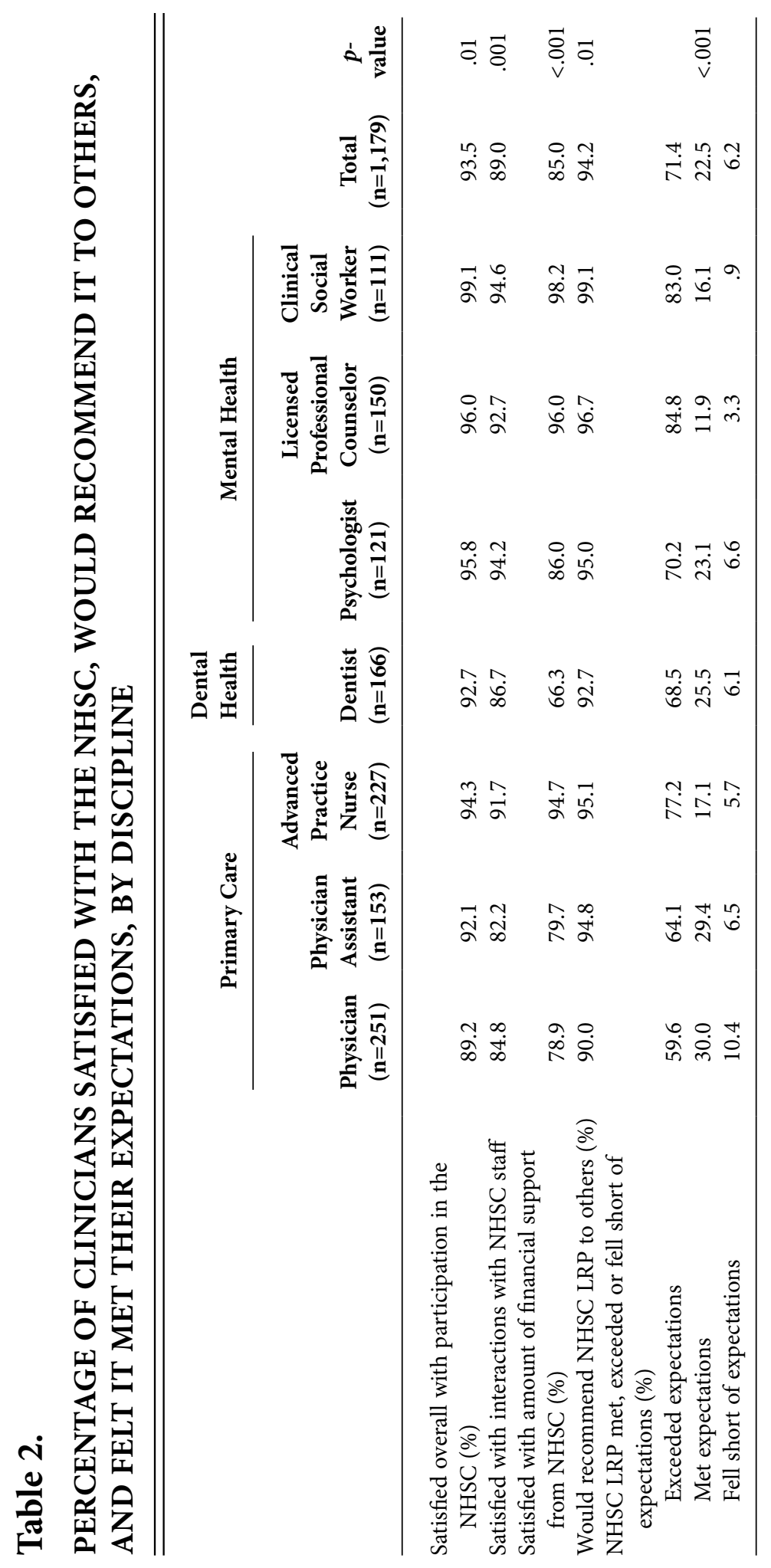




\section{Discussion}

With its organizational mission to build the clinician workforce in vulnerable communities, a key outcome for the NHSC is to be perceived positively by its clinician participants, whose personal goals are to be engaged in providing care to vulnerable communities. The NHSC's generally altruistic clinicians ${ }^{12,14,29}$ should feel that the NHSC helps them financially along their career paths through well-designed and managed programs, and respectful and responsive policies. It is therefore important to learn in this study that nearly $94 \%$ of clinicians who completed NHSC LRP contracts in recent years in these 16 states were satisfied overall with their program participation, and $94 \%$ would recommend the program to others. That the NHSC experience exceeded initial expectations for $71 \%$ of participants suggests that things went generally well with their interactions with the NHSC's policies, staff, and communications during their time in service. For historical comparison, as of 1998 only $62 \%$ of clinicians serving in the NHSC LRP were satisfied with their experiences in the NHSC, as were only $44 \%$ of Scholarship Program participants. ${ }^{14}$

A strong majority-81\% - of this study's clinicians expressed overall satisfaction with their work and practices while serving in the LRP. For comparison, 74\% of clinicians working in 500 FQHCs nationwide in 2014 reported satisfaction on a similarly scaled survey question. ${ }^{30}$ Our study's two-item overall work and practice satisfaction mean response for physicians was 4.1 on a 5-point Likert scale (mean values are not reported in Results), a significant increase from a 3.1 mean composite overall work satisfaction score reported by physicians in the NHSC's Scholarship Program in $1991 .^{31}$

Twenty years ago, only 52\% of clinicians in the LRP and $36 \%$ in the Scholarship Program reported their families were satisfied in their service communities. ${ }^{14}$ In the current study, between $73 \%$ and $87 \%$ of LRP participants reported satisfaction across six family and community fit questions, some identical to questions used in the earlier study.

Compared with clinicians in scholarship programs, experiences have consistently been found to be more positive and satisfaction greater for clinicians in loan repayment programs, both for the NHSC and states' own programs, and retention is consequently better. ${ }^{11,14,19,25,32}$ The strengths of the loan repayment model include obligating clinicians when they are older, most have families whose needs can be known, and all are in a better position to select jobs and communities that qualify for loan repayment and meet their own and their family's needs. They and their families can visit qualifying practices and communities before deciding whether to accept a position and apply for loan repayment. The NHSC's changed focus to the loan repayment approach over the past 25 years has certainly contributed to an improved NHSC service experience. Even within the LRP component of the NHSC, though, clinicians became more satisfied between 2005 and 2010, ${ }^{11}$ coinciding with the NHSC's expanded emphasis on customer service. As long recommended, ${ }^{33}$ the NHSC has expanded its communications with clinicians and now maintains a more reliable and up-to-date site eligibility list. Additionally, program rules and responses to individual clinicians' needs are now more flexible. There is a part-time service option for those who prefer to work less than full-time, many of them women. Clinicians may request a site transfer when local circumstances are unfavorable or family needs change. Clinicians are permitted to teach as they serve, 
which may bolster professional stimulation and help entice current learners into future careers serving vulnerable populations.

It is concerning that more than two-thirds of primary care clinicians and more than half of mental health clinicians in the NHSC LRP currently feel that time requirements of their jobs interfere with their personal lives. This was also true for NHSC LRP clinicians in 2005 and 2010. ${ }^{11}$ However, comparably high rates of dissatisfaction with work-life balance were recently reported for non-NHSC physicians ${ }^{34}$ and dentists, ${ }^{35}$ and these issues are also common for non-NHSC mental health clinicians. ${ }^{36}$ Work-life imbalance appears to be an unfortunate reality for U.S. clinicians generally, and it is not clear if it is any better or worse for clinicians participating in the NHSC-LRP.

Only half of these NHSC clinicians are satisfied with their income and benefits, which are comparable to rates for clinicians in the NHSC LRP in 2005 and $2010 .{ }^{11}$ Salaries are set by the practices where clinicians serve, so clinicians know what their salary and benefits will be before accepting these jobs. Perhaps their income dissatisfaction reflects the general awareness of clinicians in safety-net practices that salaries are higher in other settings, or perhaps it is due to rising educational debt levels that make current salaries inadequate. With only half of all U.S. physicians and dentists feeling fairly compensated, ${ }^{35-37}$ though, this may be another broader issue for U.S. clinicians and not directly related to Corps participation.

Satisfaction with the dollar amount of loan repayment support varied by discipline, from only two-thirds of dentists to nearly all licensed professional counselors and clinical social workers. Post-hoc analyses reveal a high inverse (-.91) correlation between a discipline's average remaining debt amount and the percentage of its clinicians satisfied with the loan repayment amount $(\mathrm{p}=.004)$. Looked at for individuals across all disciplines, those who rated the loan repayment amount "excellent" averaged $\$ 33,600$ in remaining debt at the end of their contracts, those responding "good" still held $\$ 86,300$ in debt, and clinicians responding "poor" averaged $\$ 135,500$ in remaining debt $(\mathrm{p}<.001)$.

Limitations. To keep the questionnaire brief as well as relevant to all disciplines and practice situations of NHSC participants, we selected only 21 of the most relevant 36 facet-specific satisfaction questions from the Physician Worklife Study instrument. ${ }^{21,22}$ Because this particular subset of items has not been tested previously with physicians and to our knowledge the original instrument has never been used with non-physician health disciplines, the items loaded differently in factor analyses than in the Worklife Study's physician sample. Additionally, there are no prior studies of the satisfaction of mental health clinicians of the NHSC, thus there is no data available to compare directly with this study's findings for mental health clinicians. Further, some important aspects of clinicians' job satisfaction were not assessed, including their reactions to clinic patient schedules, time pressures, and burdens of the electronic medical record.

Conclusions. The experiences of most of today's NHSC Loan Repayment Program participants and their families are positive on many measures. Most telling is that 94\% of clinicians completing LRP contracts would recommend the program to other clinicians. Satisfaction among NHSC participants is much more broadly felt now than 20 and 30 years ago, likely reflecting the NHSC's changed focus to the loan repayment program model and increased attention to its clinicians' needs. Clinicians of all disciplines participating in the NHSC LRP report they are doing well in their work and 
communities, including the program's newest, mental health disciplines. The positive work, community, and family satisfaction of LRP participants is likely contributing to the increasingly higher site-retention rates among NHSC clinicians. ${ }^{9,11}$

While dissatisfaction with work-life balance for many serving in the LRP may not differ from that for U.S. clinicians generally, this issue nevertheless can affect the quality of care clinicians provide and their retention, and thus deserves interventions by the NHSC and its service site practices. The NHSC should also develop ways to help the one quarter of spouses of NHSC clinicians who want to work, but cannot find satisfactory local employment: leaving spouses dissatisfied with the community puts clinician retention at significant risk. ${ }^{16,31}$, Data here also suggest that as an issue of clinician satisfaction and equity, the NHSC could adjust loan repayment amounts to the educational debt levels of each discipline and/or individual clinician.

With the rising educational debt of young clinicians, this study's central finding that satisfaction is high among NHSC LRP participants and the related finding of other studies of strong retention among LRP participants suggest that Congress could expand the size of the NHSC LRP workforce to enable it to correct a greater portion of the health workforce maldistribution in the U.S.

\section{Acknowledgments}

This study was funded through (a) cooperative agreement U16RH03702-14 from the Federal Office of Rural Health Policy (ORHP), U.S. Department of Health Resources and Services Administration (HRSA), to support the Multi-State Clinician Retention Collaborative, and (b) a portion of the annual dues states pay to participate in the Collaborative. ORHP and NHSC staff played no role in initiating, designing or reviewing this study and paper. Information from this study has not been previously presented or reported.

\section{References}

1. DiMatteo MR, Sherbourne CD, Hays RD, et al. Physicians' characteristics influence patients' adherence to medical treatment: results from the Medical Outcomes Study. Health Psychol. 1993 Mar;12(2):93-102.

https://doi.org/10.1037//0278-6133.12.2.93

PMid:8500445

2. Angerer P, Weigl M. Physicians' psychosocial work conditions and quality of care: a literature review. Professions and Professionalism. 2015;5(1):960.

https://doi.org/10.7577/pp.960

3. Scheepers RA, Boerebach BC, Arah OA, et al. A systematic review of the impact of physicians' occupational well-being on the quality of patient care. Int J Behav Med. 2015 Dec;22(6): 283-98.

https://doi.org/10.1007/s12529-015-9473-3

PMid:25733349 PMCid:PMC4642595

4. Konrad TR. Measures, methods, and models of doctor satisfaction: future research challenges. Professions \& Professionalism. 2015;5(1):1-16.

https://doi.org/10.7577/pp.953 
5. Grol R, Mokkink H, Smits A, et al. Work satisfaction and quality of patient care. Fam Pract. 1985 Sep;2(3):128-35.

https://doi.org/10.1093/fampra/2.3.128

PMid:4043602

6. Reddy A, Pollack CE, Asch DA, et al. The effect of primary care provider turnover on patient experience of care and ambulatory quality of care. JAMA Intern Med. 2015 Jul;175(7): 1157-62.

https://doi.org/10.1001/jamainternmed.2015.1853

PMid:25985320 PMCid:PMC5561428

7. Hall CB, Brazil K, Wakefield D, et al. Organizational culture, job satisfaction, and clinician turnover in primary care. J Prim Care Community Health. 2010 Apr 1;1(1): 29-36.

https://doi.org/10.1177/2150131909360990

PMid:23804066

8. Pathman DE, Konrad TR, Williams ES, et al. Physician job satisfaction, dissatisfaction, and turnover. J Fam Pract. 2002 Jul;51(7):593.

9. Office of the Assistant Secretary for Planning and Evaluation (ASPE). Provider retention in high need areas. Key findings in the literature. Washington, DC: U S Department of Health and Human Services, 2014. Available at: https://aspe.hhs.gov/report/provider -retention-high-need-areas/key-findings-literature.

10. Linzer M, Poplau S, Grossman E, et al. Cluster randomized trial of interventions to improve work conditions and clinician burnout in primary care: results from the Healthy Work Place (HWP) Study. J Gen Intern Med. 2015;30(8):1105-11. Epub 2015 Feb 28.

https://doi.org/10.1007/s11606-015-3235-4

PMid:25724571 PMCid:PMC4510236

11. Pathman DE, Konrad TR, Schwartz R, et al. Evaluating retention in BCRS programs: final report. Washington, DC: U S Department of Health and Human Services, 2012. Available at: https://www.shepscenter.unc.edu/wp-content/uploads/2017/08/Evaluating -Retention-in-BCRS-Programs-Final-Report_Pathman_5-4-12-1.pdf.

12. Pathman DE, Konrad TR, Ricketts TC. The comparative retention of National Health Service Corps and other rural physicians. Results of a 9-year follow-up study. JAMA. 1992 Sep 23-30;268:1552-8.

https://doi.org/10.1001/jama.268.12.1552

PMid:1518110

13. Singer JD, Davidson SM, Graham S, et al. Physician retention in community and migrant health centers: who stays and for how long? Med Care. 1998 Aug;36(8):1198-213. https://doi.org/10.1097/00005650-199808000-00008 PMid:9708592

14. Konrad TR, Leysieffer K, Stevens C. Evaluation of the effectiveness of the National Health Service Corps. Washington, DC: U S Department of Health and Human Services, 2000.

15. Health Resources and Services Administration (HRSA) Data Warehouse. National Health Service Corps (NHSC) current provider FTE summary by state report. Rockville, MD: HRSA, 2019. Available at: https://ersrs.hrsa.gov/ReportServer?/HGDW _Reports/BCD_NHSC/BCD_NHSC_FTE_State_Summary_HTML\&rc:Toolbar=false.

16. Pathman DE, Konrad TR. Growth and changes in the National Health Service Corps (NHSC) workforce with the American Recovery and Reinvestment Act. J Am Board Fam Med. 2012 Sep-Oct;25(5):723-33. 
https://doi.org/10.3122/jabfm.2012.05.110261

PMid:22956708

17. Huttinger A. 2016 NHSC participant satisfaction survey results. Presented at: The 2017 National Advisory Council on the National Health Service Corps Meeting (webinar), Rockville (MD), Jan 2017. Available at: https://nhsc.hrsa.gov/corpsexperience/aboutus /nationaladvisorycouncil/meetingsummaries/nhsc_survey_presentation_for_nac _meeting.pdf.

18. National Advisory Council on the National Health Service Corps. May 20-22, 2010 Meeting summaries. Presented at: The National Advisory Council May meeting. Bethesda (MD), May 2010. Available at: https://nhsc.hrsa.gov/sites/default/files/NHSC /NACNHSC/Meetings/meetingsummarymay2010.pdf.

19. Negrusa S, Ghosh P, Warner JT. Provider retention in high need areas: final report. Falls Church, VA: The Lewin Group, Inc., 2014. Available at: https://aspe.hhs.gov/system/files /pdf/116861/NHSC\%20Final\%20Report\%20508\%20compliance\%20July_21_2015.pdf.

20. Rauner T, Fannell J, Amundson M, et al. Partnering around data to address clinician retention in loan repayment programs: the multistate/NHSC retention collaborative. J Rural Health. 2015 Summer;31(3):231-4.

https://doi.org/10.1111/jrh.12118

PMid:25953626

21. Konrad TR, Williams ES, Linzer M, et al. Measuring physician job satisfaction in a changing workplace and a challenging environment. SGIM Career Satisfaction Study Group. Society of General Internal Medicine. Med Care. 1999 Nov;37(11):1174-82. https://doi.org/10.1097/00005650-199911000-00010

PMid:10549620

22. Williams ES, Konrad TR, Linzer M, et al. Refining the measurement of physician job satisfaction: results from the Physician Worklife Survey. SGIM Career Satisfaction Study Group. Society of General Internal Medicine. Med Care. 1999 Nov;37(11):1140-54. https://doi.org/10.1097/00005650-199911000-00006

PMid:10549616

23. Pathman $\mathrm{DE}$, Steiner $\mathrm{BD}$, Jones $\mathrm{BD}$, et al. Preparing and retaining rural physicians through medical education. Acad Med. 1999 Jul;74(7):810-20.

https://doi.org/10.1097/00001888-199907000-00016

PMid:10429591

24. Pathman DE, Konrad TR, Williams ES, et al. Physican job satisfaction, dissatisfaction, and turnover. J Fam Pract. 2002 Jul;51(7):593.

25. Pathman DE, Konrad TR, King TS, et al. Outcomes of states' scholarship, loan repayment, and related programs for physicians. Med Care. 2004 Jun;42(6):560-8.

https://doi.org/10.1097/01.mlr.0000128003.81622.ef

PMid:15167324

26. University of North Dakota. Temporary ZIP RUCA 3.10 File Access Page. Grand Forks, ND: University of North Dakota, 2014. Available at: https://ruralhealth.und .edu/ruca.

27. Eisinga R, Grotenhuis M, Pelzer B. The reliability of a two-item scale: Person, Cronbach or Spearman-Brown. Int J Public Health. 2013 Aug;58(4):637-42. Epub 2012 Oct 23.

https://doi.org/10.1007/s00038-012-0416-3

PMid:23089674

28. Health Resources and Services Administration (HRSA). Federally qualified health 
centers. Rockville, MD: HRSA, 2018. Available at: https://www.hrsa.gov/opa/eligibility -and-registration/health-centers/fqhc/index.html.

29. Porterfield D, Konrad TR, Leysieffer K, et al. Caring for the underserved: current practice of alumni of the National Health Service Corps. J Health Care for the Poor Underserved. 2003 May;14(2):256-71.

https://doi.org/10.1353/hpu.2010.0812

PMid:12739304

30. Friedberg MW, Reid RO, Timble JW, et al. Federally qualified health center clinicians and staff increasingly dissatisfied with workplace conditions. Health Aff (Millwood). 2017 Aug 1;36(8):1469-75.

https://doi.org/10.1377/hlthaff.2017.0205

PMid:28784740

31. Pathman DE, Konrad TR, Ricketts TC. The National Health Service Corps experience for rural physicians in the late 1980s. JAMA. 1994 Nov 2;272(17):1341-8.

https://doi.org/10.1001/jama.272.17.1341

PMid:7933394

32. Pathman DE, Fannell J, Konrad TR, et al. Findings of the first year retention survey of the multi-state/NHSC retention collaborative. Presented at: The Multi-state/NHSC retention collaborative Meeting, Chapel Hill (NC), Nov 2012. Available at: http:// chcworkforce.org/sites/default/files/Findings\%20of\%20Multi-State\%20NHSC\%20 Collaborative.pdf.

33. Office of Inspector General. National Health Service Corps: a survey of providers, facilities and staff. Washington, DC: U S Department of Health and Human Services, 1994. Available at: https://oig.hhs.gov/oei/reports/oei-09-91-01310.pdf.

34. Shanafelt TD, Hasan O, Dyrbye LN, et al. Changes in burnout and satisfaction with work-life balance in physicians and the general US working population between 2011 and 2014. Mayo Clin Proc. 2015 Dec;90(12):1600-13.

https://doi.org/10.1016/j.mayocp.2015.08.023

PMid:26653297

35. Lo Sasso AT, Starkel RL, Warren MN, et al. Practice setting and dentists' job satisfaction. J Am Dentl Assoc. 2015 Aug;146(8):600-609.

https://doi.org/10.1016/j.adaj.2015.03.001

PMid:26227645

36. Luther L, Gearhart T, Fukui S, et al. Working overtime in community mental health: associations with clinician burnout and perceived quality of care. Psychiatr Rehabil J. 2017 Jun;40(2):252-9. Epub 2016 Oct 27.

https://doi.org/10.1037/prj0000234

PMid:27786520 PMCid:PMC5574255

37. Grisham S. Medscape Physician Compensation Report 2017. New York, NY: Medscape, 2017. Available at: https://www.medscape.com/slideshow/compensation-2017 -overview-6008547. 